\title{
Polymerization of Butadiene. Polymerization of Butadiene with Organometallic Complexes Produced by Means of Electrolysis of Transition Metal Iodides
}

\author{
Noboru Yamazaki, Mitsuo Kase, and Takayuki Ohta \\ Tokyo Institute of Technology, Ookayama, Meguro-ku, \\ Tokyo, Japan.
}

(Received November 24, 1970)

\begin{abstract}
Polymerization of butadiene has been found on electrolysis of tetrahydrofuran solution or alcoholic solution containing nickel iodide and additives in the presence of butadiene. Polymers obtained were substantially composed of the trans-1,4 addition type. Maleic anhydride and maleic acid as additives were most effective for the polymerization. A mechanism involving univalent nickel was confirmed when compared with model compounds by using the spectroscopic method. Cobaltous iodide also yielded polymers with a predominant trans-1,4 structure, accompanied by large amounts of butadiene oligomers, and chromous iodide gave polymers with approximately equal amounts of trans-1,4, cis-1,4, and 1,2 units in good yields.

KEY WORDS Polymerization/Butadiene/Organometallic Complex/

Electrolysis / Nickel Iodide / Cobaltous lodide / Chromous Iodide /

Mechanism / Spectroscopy /
\end{abstract}

A lot of work on the polymerization of butadiene with transition metal complexes containing nickel,,$^{1-4}$ cobalt, ${ }^{5}$ ruthenium, ${ }^{6}$ and chromium $^{5}$ have been done. The nickel complexes have been precisely investigated and it has been found that the nature of halides contained in the complexes has a striking effect on the activity of the catalyst, and that the catalysts including iodide were most active for the polymerization of butadiene and gave trans1,4 polymers in good yields. ${ }^{7}$

In a previous paper, ${ }^{8}$ we reported that tetrakis(triphenylphosphine)nickel complex, which was produced by means of electrolytic reduction of nickel chloride in the presence of triphenylphoshine and butadiene in ethanolic solution, catalyzed the dimerizations of butadiene. We have also studied the polymerizations of butadiene using the same process on a variety of transition metal iodides. This paper deals with the polymerization of butadiene by electrochemical reduction of nickel iodide, cobaltous iodide, or chromous iodide in the presence of butadiene and additives such as maleic anhydride and maleic acid, which are assumed to stabilize low-valency nickel by coordinations.

\section{EXPERIMENTAL}

\section{Materials}

All solvents used herein were purified by the methods described in a previous report. ${ }^{8}$ Tetrabutylammonium iodide was prepared according to the method reported by Southworth, et al. ${ }^{9}$ Butadiene was dried with lithium aluminum hydride and freshly distilled before use. Maleic anhydride was purified by sublimation. Maleic acid, cyclooctadiene, and $t, t, t$-cyclododeca-1,5,9triene were purified by distillation.

Bis- $\pi$-allyl nickel was synthesized from nickel chloride and allylmagnesium chloride according to the method described by Wilke. ${ }^{10} \pi$-Allyl nickel iodide was prepared by the reaction of bis- $\pi$-allyl nickel and nickel iodide, $\pi$-maleic anhydride nickel iodide from bis- $\pi$-allyl nickel, nickel iodide, and maleic anhydride. ${ }^{4}$ Anhydrous nickel iodide ${ }^{11}$ was prepared from nickel carbonate $\mathrm{NiCO}_{3} \cdot 2 \mathrm{Ni}(\mathrm{OH})_{2} \cdot 4 \mathrm{H}_{2} \mathrm{O}$ and hydriodic acid, and purified by recrystallization from ethyl alcohol, followed by drying the crystal under vacuum. Anhydrous cobaltous iodide ${ }^{12}$ was prepared from cobaltous carbonate $2 \mathrm{CoCO}_{3}$. $\mathrm{Co}(\mathrm{OH})_{2} \cdot \mathrm{H}_{2} \mathrm{O}$ and hydriodic acid, and anhydrous 
chromous iodide ${ }^{13}$ by dehydrating chromous iodide hexahydrate according to the method described by Lux.

\section{Electrolysis and Polymerization}

Electrolyses were carried out in a modified $\mathrm{H}$-type glass cell, which was shown in an earlier paper. ${ }^{8}$ In a typical experiment, the cell equipped with a stopcock, which contained 20 mmoles of nickel iodide, 20 mmoles of maleic anhydride, 54 mmoles of a supporting electrolyte, tetrabutylammonium iodide, and magnetic stirring bars in both compartments, was dried under vacuum. Under vacuum 150 mmoles of tetrahydrofuran and 300 mmoles of butadiene were introduced via a trap-to-trap method into the cell cooled in a Dry-Ice and methyl alcohol bath. The cell was removed from the vacuum line and the reaction mixture in the cell was warmed to room temperature. The electrolyses were performed at room temperature in a given period, maintaining a cell voliage at $55 \mathrm{~V}$. During this time, an amount of electricity of one Faraday per mole of nickel(II) iodide, which was calculated from the strength of current and time of electrolysis, was passed through the solution. The electrolyte after the electrolysis was maintained with magnetic stirring at room temperature for an additional four days. When ethyl and methyl alcohol were used as a solvent, the supporting electrolyte could be omitted, since nickel(II) iodide, in addition, served as a supporting electrolyte in the solution.

The catholyte after stirring for four days was poured into methyl alcohol containing dilute hydrochloric acid and a small amount of $\alpha$ phenylnaphthylamine. The polymers precipitated were filtered and dried under vacuum at room temperatures. Oligomers formed were extracted with diethyl ether from the solution, from which the polymers were recovered, followed by washing the extract with water and drying it over anhydrous sodium sulfate. Oligomers were obtained by removal of the ether under reduced pressure.

\section{Analysis}

Microstructures of the polymers obtained were examined by the infrared spectroscopic method reported by Morero, et al. ${ }^{14}$ The oligomers were identined by gas chromatography (GC).
The identification by GC was conducted by comparing retention times with those of authentic samples. Infrared spectra were recorded on a Jasco IR spectrophotometer, Model IR-G, as a KBr tablet or film. A gas chromatograph (OhkuraRikagaku) fitted with a copper tube $(4 \mathrm{~mm} \times 4 \mathrm{~m})$ packed with Apiezon grease-L on Diasolid was used under the same conditions as described in an earlier report. ${ }^{8}$

\section{RESULTS AND DISCUSSION}

\section{Polymerization of Butadiene with Electrochemically} Produced Nickel Complexes

On the electrolysis of the alcoholic solutions containing nickel(II) iodide and additives such as maleic anhydride in the presence of butadiene without a supporting electrolyte like tetrabutylammonium iodide, a clear change of colour of the cathodic solution was observed during the electrolysis. An initial light yellowish green color of nickel(II) ion in the solution changed to dark green around the cathode, which discolored in air. During the agitation of the deep green solution, brown compounds gradually deposited and the green turned to a light yellowish green similar to the initial color at the end of the polymerization. The brown compounds were found to be solid butadiene polymers with a predominant trans-1,4 structure. From the solution around the anode were obtained small amounts of low polymers having the same microstructure, which might be transferred from the cathodic to the anodic compartment through the glass filter of the electrolysis cell. When tetrahydrofuran was used as a solvent instead of alcohols, the initial black color of the cathodic solution was not changed during electrolysis. The cathodic solution, after electrolysis, gave trans-1,4 polybutadiene. Results of these experiments are indicated in Table I.

\section{Effects of the Additives on the Polymerizations}

Yields of the polymers were affected by the nature of additives which are thought to stabilize low valent nickel by coordinations, and by the solvents used. In our experiments the best yield was obtained by maleic anhydride and maleic acid in the additives used. Additives such as cycloocta-1,5-diene and $t, t, t$-cyclododeca- 
Table I. Polymerization of butadiene by means of electrolysis of nickel(II) iodide in polar solvents ${ }^{a}$

\begin{tabular}{|c|c|c|c|c|c|c|c|c|}
\hline \multirow{2}{*}{$\begin{array}{c}\text { Expt } \\
\text { no. }\end{array}$} & \multirow{2}{*}{ Additive $^{b}$} & \multirow{2}{*}{ Solvent } & \multirow{2}{*}{$\begin{array}{l}\text { Amount of } \\
\text { electricity, } \\
\text { mF }\end{array}$} & \multirow{2}{*}{$\begin{array}{c}\text { Polymer } \\
\text { yield, } \\
\%\end{array}$} & \multicolumn{3}{|c|}{ Microstructure, \% } & \multirow{2}{*}[\eta]{$_{\text {toluene }}^{30^{\circ} \mathrm{C}}$} \\
\hline & & & & & trans $-1,4$ & $c i s-1,4$ & cis-1,2 & \\
\hline $\mathrm{KI}-2$ & - & DME & 10 & 3.0 & - & - & - & - \\
\hline KG-5 & - & THF & 10 & 8.8 & 96.0 & 1.5 & 2.5 & 0.14 \\
\hline KG-1 & COD & THF & 10 & 5.0 & 95.5 & 3.5 & 1.0 & 0.33 \\
\hline KG-2 & $\mathrm{CDT}$ & THF & 10 & 3.6 & 96.5 & 2.0 & 1.5 & 0.34 \\
\hline KG-10 & MAH & THF & 10 & 30 & 96.5 & 1.5 & 3.0 & 0.38 \\
\hline KK-4 & - & EtOH & 10 & trace & 99.0 & 0 & 1.0 & - \\
\hline KK-1 & MAH & EtOH & 10 & 32 & 99.0 & 0 & 1.0 & 0.12 \\
\hline KK-6 & MA & EtOH & 10 & 32 & 99.0 & 0 & 1.0 & 0.12 \\
\hline KK-3 & MAH & $\mathrm{MeOH}$ & 10 & 12 & 97.5 & 0 & 2.5 & 0.12 \\
\hline
\end{tabular}

a Condition: $\mathrm{NiI}_{2}, 20 \mathrm{mmol}$; additive, $20 \mathrm{mmol} ; \mathrm{C}_{4} \mathrm{H}_{6}, 300 \mathrm{mmol}$; solvent, $150 \mathrm{ml}$. Electrolyses in DME and THF were performed at $55 \mathrm{~V}$ for about 3 days using $108 \mathrm{mmol}$ of $\mathrm{Bu}_{4} \mathrm{NI}$ as a supporting electrolyte and in $\mathrm{MeOH}$ and $\mathrm{EtOH}$ at $55 \mathrm{~V}$ for about several hours in the absence of $\mathrm{Bu}_{4} \mathrm{NI}$. After electrolysis the electrolyte was maintained with magnetic stirring for four days.

b COD, cycloocta-1,5-diene; CDT, $t, t, t$-cyclododeca-1,5,9-triene; MAH, maleic anhydride; Ma, maleic acid.

1,5,9-triene were not so effective for the polymerization of butadiene.

$\pi$-cycloocta-1,5-diene nickel(I) halide complexes which initiate polymerizations of butadiene ${ }^{15}$ were not electrochemically prepared in dimethoxyethane and alcohols. ${ }^{16}$ Cycloocta-1,5-diene and cyclododeca-1,5,9-triene are thought to be electron acceptors which are poorer than maleic anhydride and maleic acid, although donoracceptor properties of ligands depend on the nature of the central atom and its environment. They seem not to have $\pi$-acceptibilities enough to stabilize low valency nickel produced by electrolytic reduction, and hence are not effective for polymerization. On the other hand, the electrolysis of nickel(II) iodide in the presence of maleic anhydride and maleic acid yielded nickel(I) complexes (This will be described in the next section) and gave trans-1,4 polymers.

It has been known that univalent nickel complexes containing iodide or bromide, e.g., $\pi$-allylnickel(I) iodide, ${ }^{2} \pi$-crotylnickel(I) iodide, ${ }^{2}$ and $\pi$-methylfumarate nickel(I) bromide, ${ }^{4}$ catalyzed the polymerization of butadiene to give predominantly trans- 1,4 polymers. The microstructure of the polymers obtained herein was similar to that of these polymers. This fact suggests a similarity of the propagation mechanism in these polymerization systems.

\section{A Mechanism for the Polymerizations}

A Polymerization of Butadiene with a Nickel(I) Complex Which was Prepared by Means of Electrolysis. On the electrolysis of an ethanolic solution containing equimolar amounts of nickel(II) iodide and maleic anhydride in the absence of butadiene, an initial light yellowish green color of the solution changed to dark green as in the presence of butadiene. After the electrolysis butadiene was added to the dark green solution in the cathodic compartments and the solution was maintained at room temperature for four days with stirring. During this time brown compounds precipitated from the cathodic solution, the color of which were gradually changed to the initial light yellowish green. The precipitate was a solid polymer with $99.5 \%$ of trans $-1,4$ and $0.5 \%$ of 1,2 unit (a polymer yield, 16\%; $\left.[\eta]_{\text {toluene }}^{30^{\circ} \mathrm{C}}, 0.14\right)$. In a previous paper tetrakis(triphenylphosphine)nickel complex which catalyzed the dimerizations of butadiene was obtained by the electrochemical reduction of nickel(II) chloride in the presence of triphenylphosphine. These findings led us to assume that nickel(II) iodide in the presence of maleic anhydride was electrochemically reduced to a low-valent nickel complex which catalyzed the polymerization of butadiene to yield the trans1,4 polymers. 
A Comparison of Visible Spectra of Electrolysis Systems and Related Reaction Mixtures. Results of the measurements are shown in Table II and Figure 1. A yellowish orange ethanolic solution of bis- $\pi$-allylnickel $(O)$ complex showed a maximum absorption band at $4.05 \mathrm{~m} \mu$ due to $\mathrm{Ni}(\mathrm{O})(\mathrm{KN}-5)$. When a stoichiometric amount of nickel(II) iodide was added to the solution, the yellowish orange color of the solution turned to dark red and the absorption band at $405 \mathrm{~m} \mu$ shifted to $425 \mathrm{~m} \mu$ (KN-4) which may be due to a resulting $\pi$-allylnickel(I) iodide. On addition of maleic anhydride, the color of the solution changed from dark red to dark green, which may be attributed to $\pi$-maleic anhydride nickel(I) iodide, ${ }^{4}$ but the absorption band at $425 \mathrm{~m} \mu$ did not shift (KN-3). When butadiene was introduced to the dark green solution, the brown compound was gradually precipitated after one day, and was trans-1,4 polymers of butadiene(KN-2). Similar phenomena were observed in electrolysis systems. A mixture of stoichiometric amounts of both nickel(II) iodide and maleic anhydride in ethyl alcohol exhibited a maximum absorption band at $350 \mathrm{~m} \mu$ owing to $\mathrm{Ni}(\mathrm{II})(\mathrm{KN}-6)$. On electrolysis of the ethanolic solution of the mixture, the initial light yellowish green color of the solution gradually changed to dark green. The absorption band at $360 \mathrm{~m} \mu$ decreased and a new band appeared at $425 \mathrm{~m} \mu$ attributable of $\mathrm{Ni}(\mathrm{I})(\mathrm{KN}-7)$. This indicates that nickel(II) iodide was electrochemically reduced to give $\pi$-maleic anhydride nickel(I) iodide complex. On addition of butadiene to the dark green solution after the electrolysis, the brown compounds composed of the

Table II. Measurements of visible spectra of reaction mixtures in ethyl alcohol ${ }^{\mathrm{a}}$

\begin{tabular}{cccccccc}
\hline $\begin{array}{c}\text { Expt } \\
\text { no. }\end{array}$ & $\begin{array}{c}\mathrm{NiI}_{2}, \\
\mathrm{mmol}\end{array}$ & $\begin{array}{c}\mathrm{MAH}, \\
\mathrm{mmol}\end{array}$ & $\begin{array}{c}\left(\pi-\mathrm{C}_{3} \mathrm{H}_{5}\right)_{2} \mathrm{Ni}, \\
\mathrm{mmol}\end{array}$ & $\begin{array}{c}\text { Butadiene, } \\
\mathrm{mmol}\end{array}$ & $\begin{array}{c}\text { Amount of } \\
\text { electricity, } \\
\mathrm{mF}\end{array}$ & $\begin{array}{c}\text { Colour of } \\
\text { solution }\end{array}$ & $\begin{array}{c}\lambda \text { max, } \\
\mathrm{m} \mu\end{array}$ \\
\hline $\mathrm{KN}-5$ & - & - & 5 & - & - & Yellowish orange & 405 \\
$\mathrm{KN}-4$ & 10 & - & 5 & - & - & Dark red & 425 \\
$\mathrm{KN}-3$ & 10 & 10 & 5 & - & - & Dark green & 425 \\
$\mathrm{KN}-2$ & 10 & 10 & 5 & 100 & - & Dark green & 425 \\
$\mathrm{KN}-6$ & 5 & 5 & - & - & - & Yellowish green & 360 \\
$\mathrm{KN}-7$ & 5 & 5 & - & - & 5 & Dark green & 425 \\
$\mathrm{KN}-9$ & 5 & 5 & - & $(50)^{\mathrm{b}}$ & 5 & Dark green & 425 \\
$\mathrm{KN}-8$ & 5 & 5 & - & 50 & 5 & Dark green & 425 \\
\hline
\end{tabular}

a The electrolysis and measurements of visible spectra were carried out in a quartz cell equipped with platinum electrodes using $\mathrm{Bu}_{4} \mathrm{NI}$ as a supporting electrolyte.

b After electrolysis 50 mmoles of butadiene were added.

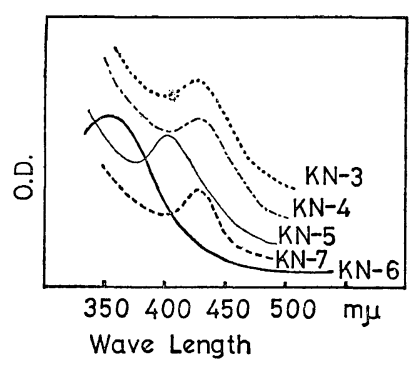

Figure 1. Visible spectra of electrolysis systems and related reaction mixtures in ethyl alcohol: $\mathrm{NH}-6, \mathrm{NiI}_{2} / \mathrm{MAH}=1 / 1$ (molar ratio); $\mathrm{KH}-7$, after electrolysis of $\mathrm{KN}-6$; $\mathrm{KN}-5$, bis $(\pi$-allyl $)$ nickel $(\mathrm{O})$; $\mathrm{KN}-4$, bis $\left(\pi\right.$-allyl)nickel $(\mathrm{O}) / \mathrm{NiI}_{2}=1 / 2 ; \mathrm{KN}-3, \mathrm{NiI}_{2} /$ $\operatorname{bis}(\pi$-allyl)nickel $(\mathrm{O})=2 / 2 / 1$. trans-1,4 polymers were deposited as seen in the experiments of the electrolysis in the presence of butadiene(KN-9).

$I R, N M R$ Spectra, and Gel-Permeation Chromatograms of the Polymers. In the IR and NMR spectra of the polymers of butadiene obtained in the presence of maleic anhydride, no absorption bands assigned to a stretching vibration of the carbonyl group and protons attached to the carbon atom adjacent to the carbonyl group of maleic anhydride could be detected, whereas an absorption band due to methyl group was observed at $1380 \mathrm{~cm}^{-1}$ and $8.30-8.40 \tau$ (Figures 2 and 3 ). In a previous paper, ${ }^{8}$ we reported that hydrooligomers and alkoxylated 


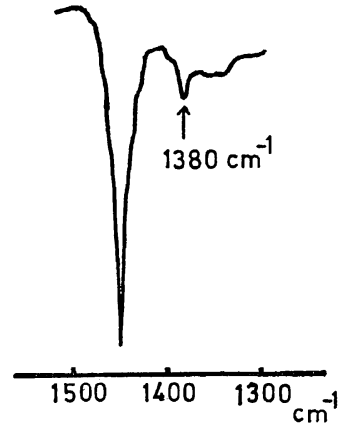

Figure 2. IR spectrum of polybutadiene obtained by means of electrolysis of nickel(II) iodide; observed in benzene at room temperature.

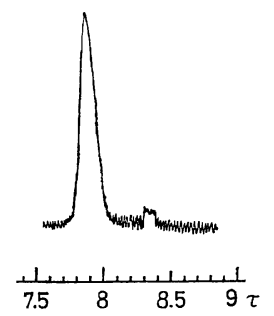

Figure 3. NMR spectrum of polybutadiene obtained by means of electrolysis of nickel(II) iodide; observed in benzene at room temperature.

oligomers of butadiene were obtained by the electrochemical reduction of alcoholic solutions containing nickel(II) compounds and butadiene, and it was suggested that butadiene reacted with hydrogen which was derived from solvents Hence, the obtainable polymer had a methyl group at the end. A gel-permeation chromatogram of the polymer obtained herein showed only one peak, which indicates that the polymer was produced on one catalytic species.

An Electrochemical Reduction Process of Nickel (II) Iodide. It was previously reported that a first electrode process of the electrochemical reduction of nickel(II) chloride in the presence of pyridine and triphenylphosphine in methyl alcohol was predominantly a direct electron transfer from cathode to nickel(II) ion. ${ }^{8}$ In the present systems the same process can be proposed, based on the facts described in the previous paper. The resulting nickel(I) complex is thought to form via two processes, namely (A) reduction of $\mathrm{Ni}(\mathrm{II})$ to $\mathrm{Ni}(\mathrm{I})$ on nickel atoms, resulting in the $\pi$-crotyl group.

$$
\mathrm{Ni}(\mathrm{II}) \stackrel{e}{\longrightarrow} \mathrm{Ni}(\mathrm{I})
$$

and (B) reduction of $\mathrm{Ni}(\mathrm{II})$ to $\mathrm{Ni}(\mathrm{O})$, followed by oxidation with nickel(II) iodide

$$
\mathrm{Ni}(\mathrm{II}) \stackrel{2 \mathrm{e}}{\longrightarrow} \mathrm{Ni}(\mathrm{O}) \stackrel{\mathrm{NiI}_{2}}{\longrightarrow} \mathrm{Ni}(\mathrm{I})
$$

The polymerizations of butadiene by means of the electrolytic reduction of nickel(II) iodide in the presence of maleic anhydride and maleic acid were accompanied by only small amounts of metallic nickel deposited on the cathode, while in the absence of maleic anhydride and maleic acid by large amounts of metallic nickel. Although attempts to ascertain the process by the polarographic method failed, the results described above suggest that nickel(I) complexes are produced mainly through process (B).

On the basis of these results, the polymerization of butadiene by means of electrolysis of alcoholic solutions containing nickel(II) iodide, maleic anhydride, and butadiene may proceed as follows: Nickel(II) iodide is electrochemically reduced to zerovalent nickel, which reacts with nickel(II) iodide to yield $\pi$-maleic anhydride nickel(I) iodide. Maleic anhydride is then displaced by excess of butadiene and one molecule of butadiene on the nickel atom derives a hydrogen atom from the solvent used, forming $\pi$-crotylnickel(I) iodide. An insertion of butadiene into the $\pi$-allyl nickel bond initiates the

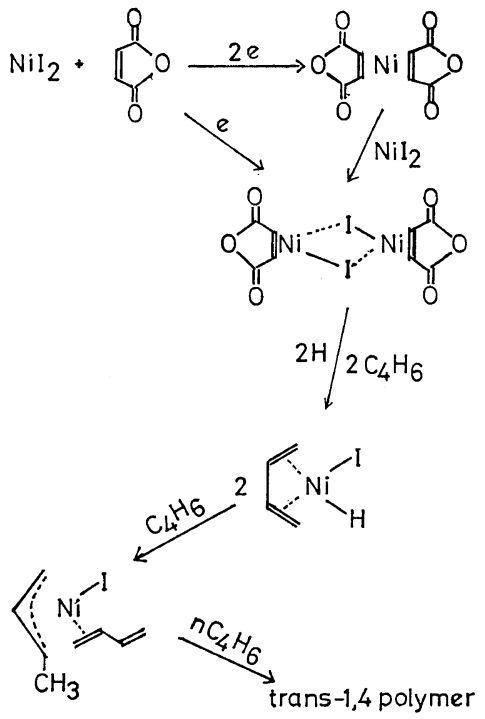

Figure 4. A scheme for the polymerization. 
Table III. Polymerization of butadiene by means of electrolysis of cobaltous iodide and chromous iodide in tetrahydrofuran ${ }^{\mathrm{a}}$

\begin{tabular}{|c|c|c|c|c|c|c|c|c|c|}
\hline \multirow{2}{*}{$\begin{array}{c}\text { Expt } \\
\text { no. }\end{array}$} & \multirow{2}{*}{$\begin{array}{l}\text { Metal } \\
\text { salt }\end{array}$} & \multirow{2}{*}{ Additive } & \multirow{2}{*}{$\begin{array}{c}\text { Amount of } \\
\text { electricity, } \\
\text { mF }\end{array}$} & \multirow{2}{*}{$\begin{array}{c}\text { Dligomer } \\
\text { yield, } \\
\%\end{array}$} & \multirow{2}{*}{$\begin{array}{c}\text { Polymer } \\
\text { yield, } \\
\%\end{array}$} & \multicolumn{3}{|c|}{ Microstructure, $\%$} & \multirow{2}{*}[\eta]{$_{\text {toluene }}^{30^{\circ} \mathrm{C}}$} \\
\hline & & & & & & trans $-1,4$ & cis- 1,4 & $c i s-1,2$ & \\
\hline $\mathrm{KH}-2$ & $\mathrm{CoI}_{2}$ & - & 10 & 35 & 7.5 & 84.5 & 6.0 & 9.5 & 0.76 \\
\hline $\mathrm{KH}-4^{\mathrm{b}}$ & $\mathrm{CoI}_{2}$ & - & 10 & 0 & 3.8 & 89.0 & 5.0 & 6.0 & 0.64 \\
\hline $\mathrm{KH}-3$ & $\mathrm{CoI}_{2}$ & MAH & 10 & 3.8 & 6.3 & 70.0 & 13.5 & 16.5 & 0.33 \\
\hline KH-7 & $\mathrm{CrI}_{2}$ & - & 7 & 0 & 109 & 32.0 & 25.5 & 42.5 & 0.16 \\
\hline KH-6 & $\mathrm{CrI}_{2}$ & MAH & 6 & 0 & 0 & - & - & - & - \\
\hline
\end{tabular}

a Conditions: $\mathrm{CoI}_{2}\left(\mathrm{CrI}_{2}\right), 10 \mathrm{mmol}$; additive, $10 \mathrm{mmol} ; \mathrm{C}_{4} \mathrm{H}_{6}, 300 \mathrm{mmol} ; \mathrm{THF}, 150 \mathrm{ml} ; n$-Bu $\mathrm{BI}_{4}, 108$ mmol. Electrolyses were performed at $55 \mathrm{~V}$ for about three days. After the electrolysis the electrolyte was maintained with stirring for an additional four days.

b $\mathrm{CoI}_{2}, 20 \mathrm{mmol}$.

\section{polymerization (Figure 4).}

\section{Polymerization of Butadiene with Electrochemically} Produced Cobalt and Chromium Complexes

Polymerizations of butadiene by means of electrolyses of cobaltous and chromous iodide in the presence of butadiene were carried out in tetrahydrofuran in the same way as in the experiments with nickel(II) iodide. These results are shown in Table III.

By the electrochemical reaction of cobaltous iodide in tetrahydrofuran numbers of butadiene oligomers were produced with small amounts of polymers consisting mainly of trans-1,4 units. One of the oligomers was identified by gaschromatographic analysis as 3-methylhepta-1,4,6triene, but other oligomers composed of trimers and tetramers of butadiene were not characterized yet. An addition for maleic anhydride to the electrolysis system did not give metallic cobalt and showed a considerable decrease in the yield of oligomers but not in the yield of the polymers. An electrolytic reduction of 2fold excess of cobaltous iodide yielded polymers (KH-4) but neither oligomers nor metallic cobalt. It has been reported that a zerovalent cobalt complex tris- $\pi$-allylcobalt catalyzed the dimerization of butadiene to 3-methylhepta-1,4,6-triene ${ }^{5}$ and that an univalent cobalt complex bis- $\pi$ allylcobalt iodide initiated the polymerization of butadiene to yield cis-1,4 polymers. ${ }^{5}$ From these results, it is assumed that zero- and univalent cobalt complexes formed by the electrochemical reduction of cobaltous iodide catalyzed the oligomerization and polymerization of buta- diene, respectively.

The use of chromous iodide instead of cobaltous iodide gave high conversions to viscous polybutadiene which was composed of approximately equal amounts of trans-1,4, cis-1,4, and 1,2-units.

Further investigations on the oligomerizations and polymerizations of butadiene by the electrolytic reduction of cobaltous and chromous iodide are now being carried out.

\section{REFERENCES}

1. F. Dawan and Ph. Teyssie, J. Polym. Sci., Part B, 7, 111 (1969).

2. J. Furukawa and H. Morimura, ibid., Part B, 7, 541 (1969).

3. J. Furukawa and H. Morimura, ibid., Part B, 6, 869 (1968).

4. M. Dubini and F. Montino, Chem. Commun., 749 (1969).

5. G. Wilke, B. Bogdanovic, P. Hardt, P. Heimbach, W. Kein, M. Kroner, W. Oberkirch, K. Tanaka, E. Steinrucke, D. Walter, and H. Zimmermann, Angew. Chem., 78, 157 (1966).

6. K. Hiraki and H. Hirai, J. Polym. Sci., Part $B, 7,449$ (1969).

7. A. D. Jenkins, "Progress in Polymer Science," Vol. 1, Pergamon Press, Ltd., New York, N.Y., 1967, p 131.

8. T. Ohta, K. Ebina, and N. Yamazaki, Bull. Chem. Soc. Japan, in press.

9. B. C. Southworth and R. Osteryoung, Anal. Chem., 33, 208 (1961).

10. G. Wilke and B. Bogdanovic, Angew. Chem., 73, 756 (1961).

11. Gmelin-Institute, “Gmelins Handbuch," Verlag 
Chemie, G.m.b.H., Berlin, 1953, Ni B, 606.

12. Gmelin-Institute, "Gmelins Handbuch," Verlag Chemie, G.m.b.H., Berlin, 1961, Co A, 595.

13. H. Lux and G. Illman, Chem. Ber., 2143 (1968).

14) D. Morero, A. Santambrogio, L. Porri, and
F. Clampelli, Chim. Ind. (Milan), 41, 758 (1959).

15) L. Porri, M. C. Callazzi, and G. Vitulli, $J$. Polym. Sci., Part B, 5, 629 (1957).

16) T. Ohta and N. Yamazaki, unpublished data. 